\title{
Teores foliares, acúmulo e partição de macronutrientes na cultura da abóbora irrigada com água salina ${ }^{1}$
}

\author{
Gilcimar A. do C armo², Francisco R. A. de O liveira ${ }^{3}$, José F. de Medeiros ${ }^{3}$, \\ Francisco de A. de O liveira ${ }^{3}$, Marcos de S. Campos $^{3} \&$ D janira C. de Freitas ${ }^{3}$
}

\begin{abstract}
RESU MO
$\mathrm{Na}$ região de M ossoró a área cultivada com abóbora tem sofrido um aumento considerável, em virtude da demanda externa. Este trabalho teve como objetivo avaliar o efeito da salinidade da água de irrigação sobre os teores, o acúmulo e partição de macronutrientes no tecido vegetal da abóbora. 0 experimento foi desenvolvido no período de fevereiro a abril de 2008, em condições de campo, na Fazenda Experimental da U FERSA, M ossoró, RN . O delineamento experimental adotado foi o de blocos completos casualizados, com quatro repetições. Os tratamentos foram compostos da aplicação de irrigação com cinco níveis de salinidade da água medida ao longo do ciclo $\left(\mathrm{S}_{1}=0,66 ; \mathrm{S}_{2}=2,11 ; \mathrm{S}_{3}=3,29 ; \mathrm{S}_{4}=4,11\right.$ e $\left.\mathrm{S}_{5}=4,38 \mathrm{dS} \mathrm{m}^{-1}\right)$. O $\mathrm{s}$ teores foliares de nitrogênio, fósforo, potássio, cálcio e magnésio, foram avaliados em quatro épocas: 18, 28, 42 e 56 dias após a germinação (DAG) durante o ciclo da cultura. A salinidade da água de irrigação afetou a absorção de nutrientes pela cultura da abóbora. Os maiores teores de fósforo, potássio e magnésio no tecido vegetal da abóbora, foram obtidos na fase intermediária do ciclo da cultura. Os teores de nitrogênio diminuíram enquanto os teores de cálcio aumentaram ao longo do ciclo da cultura. A absorção de nutrientes pela cultura da abóbora ocorreu na seguinte ordem: $\mathrm{K}>\mathrm{N}>$ $\mathrm{Ca}>\mathrm{P}>\mathrm{Mg}$, obtendo-se o total de $126,5,72,7,42,0,15,5$ e 9,7 $\mathrm{kg} \mathrm{ha}^{-1}$, sendo exportados para os frutos cerca de $64,1,82,8,73,7,11,2$ e $50,7 \%$, respectivamente.
\end{abstract}

Palavras-chave: Curcubita moscata, nutrição de plantas, condutividade elétrica

\section{Leaf content, accumulation and partitioning of nutrients in pumpkin crop irrigated with saline water}

\begin{abstract}
In the region of Mossoró, the area planted with pumpkin has increased substantially because of external demand. This study aimed to assess the effect of irrigation with saline water on the concentration N, P, K, Ca and $\mathrm{Mg}$ in vegetal tissue of the pumpkin. This experiment was carried out from February to April 2008, under field conditions at the Experimental Farm of U FERSA, M ossoró, RN. The experimental design was in completely randomized block with four replications. The treatments consisted of five levels of irrigation water salinity measured along the cycle $\left(\mathrm{S} 1=0.66, \mathrm{~S} 2=2.11, \mathrm{~S} 3=3.29, \mathrm{~S} 4=4.11\right.$ and $\mathrm{S} 5=4.38 \mathrm{dS} \mathrm{\textrm {m } ^ { - 1 }}$ ). The nitrogen, phosphorus, potassium, calcium and magnesium contents were evaluated in leaf at four stages $(18,28,42$ and 56 days after germination (DAG) during the crop cycle. The salinity of irrigation water affected the absorption of nutrients by the pumpkin. The highest levels of phosphorus, potassium and magnesium in the leaves of the pumpkin were obtained at the intermediate stage of the crop cycle. The content of nitrogen decreased, while the calcium increased over the crop cycle. Nutrient uptake by the pumpkin crop occurred in the following order: $\mathrm{K}>\mathrm{N}>\mathrm{Ca}>\mathrm{P}>\mathrm{Mg}$, scoring a total of $126.5,72.7,42.0$, 15.5 and $9.7 \mathrm{~kg} \mathrm{ha}^{-1}$, the fruits exported about $64.1,82.8,73.7,11.2$ and $50.7 \%$, respectively.
\end{abstract}

Key words: Curcubita moscata, plant nutrition, electrical conductivity

\footnotetext{
Trabalho submetido e selecionado no primeiro Simpósio Brasileiro de Salinidade realizado de 12-15/10/2010 em Fortaleza, Ceará, Brasil

${ }^{1}$ Parte da Tese de D outorado do primeiro autor, apresentada ao D outorado em Fitotecnia da U niversidade Federal Rural do Semi-Árido (UFERSA) ${ }^{2}$ IFCE/Campus Iguatu, Rua Deoclécio Lima Verde, s/n, Iguatu, CE. E-mail: galcar60@hotmail.com

${ }^{3}$ DCAT/U FERSA, BR 110, CP. 137, CEP. 59.625-900, Mossoró,RN. Fone: (84) 3315-1799. E-mail: ronaldoindep@yahoo.com.br; jfrancismar.rn@uol.com.br; thikaoamigao@ufersa.edu.br; marcosufersa@hotmail.com; djanira_freitas@hotmail.com
} 


\section{INTRODUÇÃO}

A cultura da abóbora é bastante difundida na região Nordeste do Brasil, onde é considerada como de subsistência. No entanto, em função de uma demanda surgida no mercado externo, iniciou-se o cultivo de abóbora tipo Butternut, cuja área plantada nos anos de 2004 e 2005 foi de aproximadamente 500 ha, e o volume exportado nesse período foi, respectivamente, de 330 e 1.624 ton (SIN, 2005).

O semiárido nordestino apresenta características climáticas bem definidas, como precipitações escassas e irregulares além de elevada evapotranspiração. Assim, muitos produtores da região acatam a irrigação como a tecnologia que mais contribui para o aumento da produtividade; no entanto, devido à escassez de recursos hídricos de boa qualidade têm-se aplicado, na irrigação, água de qualidade inferior, o que pode salinizar o solo e reduzir o rendimento das culturas. No entanto, seu uso inadequado, aliado à utilização de águas com elevada concentração de sais, tem sido uma das principais causas da salinização do solo (Cardona et al., 2004).

Em virtude da condição de salinização do solo, podem ocorrer desordens nutricionais, induzindo relações antagônicas entre nutrientes na planta, o que reduz significativamente os rendimentos das culturas (Grattan \& Grieve, 1993). Segundo Freire \& Rodrigues (2009), os problemas decorrentes da salinização dos solos resultam em abandono das terras por parte dos produtores, principalmente nos perímetros irrigados do Nordeste Brasileiro.

Os sais, além de afetarem a disponibilidade de água, causam distúrbios nutricionais à planta, dependendo do sal e do genótipo vegetal. A presença de íons em excesso pode impedir a absorção de elementos essenciais ao crescimento da planta, levando ao desbalanceamento nutricional (Tester \& Davenport, 2003).

A redução no acúmulo de fotoassimilados em plantas cultivadas sob estresse salino é uma das características mais observadas (Silva et al., 2003), tal como a absorção de nutrientes, de forma que essas plantas podem apresentar desbalanço nutricional. Maia et al. (2005) e Silva et al. (2008), ambos trabalhando com a cultura do meloeiro, observaram que as quantidades de nitrogênio, fósforo, potássio e magnésio exportados pelas plantas, diminuíram com o aumento da salinidade da água de irrigação.

O conhecimento sobre o acúmulo e partição de fotoassimilados e nutrientes, pode contribuir para melhorar a produtividade das culturas por meio do incremento na produção de biomassa total, melhorando a transferência de assimilados para as partes colhidas da planta, favorecendo a eficiência do uso de fertilizantes.

Com o exposto, este trabalho foi desenvolvido com o objetivo de avaliar o efeito da salinidade da água de irrigação sobre os teores, acúmulo e partição de macronutrientes na cultura da abóbora tipo Butternut.

\section{MATERIAl E MÉTOdos}

O experimento foi desenvolvido no período de 25/02/2008 a 29/04/2008, em condições de campo, nas coordenadas $5^{\circ} 03^{\prime}$ $37^{\prime \prime} \mathrm{S}$ de latitude, $37^{\circ} 23^{\prime} 50^{\prime \prime} \mathrm{W}$ de longitude e $72 \mathrm{~m}$ de altitude, no município de Mossoró, RN. De acordo com a classificação climática de Köppen, o clima de Mossoró é do grupo BSwh', muito quente e com estação chuvosa no verão, atrasando-se para o outono, apresentando temperatura média de $27,4^{\circ} \mathrm{C}$, precipitação pluviométrica anual muito irregular, com média de $673,9 \mathrm{~mm}$ e umidade relativa do ar de 68,9\% (Carmo Filho \& Oliveira, 1989).

O solo da área experimental é classificado como um Latossolo Vermelho Amarelo Argissólico franco-arenoso, conforme classificação metodológica proposta pela EMBRAPA (1999). Amostras de solo foram coletadas na área experimental, para a caracterização física e química (Tabela 1), a fim de promover manejo adequado da irrigação e da adubação, que foi realizada via fertigação (EMBRAPA, 1997). O solo do local para a camada de $0-20 \mathrm{~cm}$ apresenta densidade do solo igual a $1,53 \mathrm{~g} \mathrm{~cm}^{-3}$, densidade de partículas de $2,64 \mathrm{~g} \mathrm{~cm}^{-3}$ com conteúdo de areia, silte e argila de 82, 4 e 14\%, respectivamente.

Tabela 1. Características químicas e físicas do solo utilizado no experimento, 2009

\begin{tabular}{lcc}
\hline \multicolumn{1}{c}{ Características } & Unidade & Valor \\
$\mathrm{pH}\left(\mathrm{H}_{2} \mathrm{O}\right)$ & & 6,00 \\
$\mathrm{P}$ & $\left(\mathrm{mg} \mathrm{kg}^{-1}\right)$ & 30,0 \\
$\mathrm{~K}^{+}$ & $\left(\mathrm{cmol}_{\mathrm{c}} \mathrm{dm}^{-3}\right)$ & 0,28 \\
$\mathrm{Ca}^{2+}$ & $\left(\mathrm{cmol}_{\mathrm{c}} \mathrm{dm}^{-3}\right)$ & 3,20 \\
$\mathrm{Mg}^{2+}$ & $\left(\mathrm{cmol}_{\mathrm{c}} \mathrm{dm}^{-3}\right)$ & 1,00 \\
$\mathrm{Na}^{+}$ & $\left(\mathrm{cmol}_{\mathrm{c}} \mathrm{dm}^{-3}\right)$ & 0,31 \\
$\mathrm{Soma}^{-3}$ de Bases & $\left(\mathrm{cmol}_{\mathrm{c}} \mathrm{dm}^{-3}\right)$ & 4,79 \\
$\mathrm{Al}^{3+}$ & $\left(\mathrm{cmol}_{\mathrm{c}} \mathrm{dm}^{-3}\right)$ & 0,05 \\
\hline Curva de retenção - Coeficientes da Eq. $\mathrm{I}^{*}$ & \\
$\alpha$ & & 0,1972 \\
$\theta \mathrm{S}$ & $\left(\mathrm{m}^{3} \mathrm{~m}^{-3}\right)$ & 0,3650 \\
$\theta \mathrm{r}$ & $\left(\mathrm{m}^{3} \mathrm{~m}^{-3}\right)$ & 0,0460 \\
$\mathrm{n}$ & & 2,4090 \\
$\mathrm{~m}$ & & 0,5849 \\
$\mathrm{R}^{2}$ & & 0,9990 \\
${ }^{*} \mathrm{~h}$ expresso em, $\mathrm{kPa}$ &
\end{tabular}

Visando à determinação da curva de retenção, coletaram-se amostras na profundidade de $0-25 \mathrm{~cm}$; para pressões menores que $10 \mathrm{kPa}$, utilizou-se a mesa de tensão (funil de Hainnes) e, para as tensões acima de $10 \mathrm{kPa}$, a câmara de Richards. O ajuste da curva foi realizado de acordo com a metodologia proposta de van Genuchten (1980), através da umidade do solo pode ser descrita pela Eq. 1:

$$
\theta(h)=\theta r+\frac{(\theta s-\theta r)}{\left[1+(\alpha h)^{n}\right]^{m}}
$$

sendo:

$\theta(\mathrm{h})$ - umidade do solo $\left(\mathrm{cm}^{3} \mathrm{~cm}^{-3}\right)$ para um valor de $\mathrm{h}$

Or - umidade residual do solo $\left(\mathrm{cm}^{3} \mathrm{~cm}^{-3}\right)$, obtido pelo modelo por extrapolação

$\theta \mathrm{s}$ - umidade de saturação do solo $\left(\mathrm{cm}^{3} \mathrm{~cm}^{-3}\right)$

$\alpha, \mathrm{n}$ e m - parâmetros de ajuste do modelo

$\mathrm{h}$ - módulo potencial matricial $(\mathrm{kPa})$ 
O delineamento experimental adotado foi o de blocos completos casualizados, com quatro repetições. Os tratamentos foram compostos da aplicação de irrigação com cinco níveis de salinidade (S) da água medida ao longo do ciclo $\left(S_{1}=0,66 ; S_{2}=2,11 ; S_{3}=3,29 ; S_{4}=4,11\right.$ e $\left.S_{5}=4,38 \mathrm{dS} \mathrm{m}^{-1}\right)$. As águas salinas foram produzidas previamente, por meio da mistura da água de menor salinidade $\left(\mathrm{S}_{1}\right)$ com água de maior salinidade $\left(\mathrm{S}_{5}\right)$. As parcelas experimentais foram constituídas de três fileiras de plantas de $20 \mathrm{~m}$, sendo duas bordaduras e a fileira central a parcela útil, para produção.

A água de menor salinidade $\left(\mathrm{S}_{1}\right)$ foi oriunda de poço artesiano profundo, com a seguinte concentração química: $\mathrm{CE}$ $\left(\mathrm{dS} \mathrm{m}{ }^{-1}\right)=0,57 ; \mathrm{Ca}^{2+}=3,1 ; \mathrm{K}^{+}=0,44 ; \mathrm{Mg}^{2+}=0,9 ; \mathrm{Na}^{+}=2,16 ; \mathrm{Cl}^{-}$ $=2,4 ; \mathrm{CO}_{3}^{-}=1,4 ; \mathrm{HCO}_{3}^{-}=4,6 ; \mathrm{pH}=8,8 ; \mathrm{RAS}=1,97 \mathrm{eRAS}_{\mathrm{aj}}=$ $1,80\left(\mathrm{mmol} \mathrm{L}^{-1}\right)$. A água de maior salinidade $\left(\mathrm{S}_{5}\right)$ foi produzida previamente pela dissolução dos sais de $\mathrm{NaCl}, \mathrm{CaCl}_{2} \cdot 2 \mathrm{H}_{2} \mathrm{O}$ e $\mathrm{MgSO}_{4} \cdot 7 \mathrm{H}_{2} \mathrm{O}$, de modo que a relação catiônica $\mathrm{Na}: \mathrm{Ca}: \mathrm{Mg}$ foi de 7:2:1.

Utilizou-se a cultivar da abóbora híbrido F1 "Atlas" (tipo Butternut americana). Este híbrido de abóbora apresenta rama curta, alta precocidade e produtividade, em que os frutos apresentam casca de coloração creme, com boa uniformidade de formato, tamanho e cor.

O preparo do solo consistiu de uma aração seguida de gradagem, elevação de canteiros com altura em torno de $0,20 \mathrm{~m}$ e colocação do mulch (dupla face: branco/preto), deixando-se a face de cor branca para cima. O cultivo no campo foi feito através de semeadura direta, no dia 25/02/2008, fazendo-se replantio no dia $04 / 03 / 2008$. O espaçamento utilizado no experimento foi o de $2,0 \times 0,5 \mathrm{~m}$, resultando numa densidade de 10.000 plantas por hectare.

O manejo da irrigação foi realizado diariamente, com base na estimativa da evapotranspiração máxima da cultura (ETm), conforme método proposto pela FAO 56 (Allen et al., 1998), aplicando-se a metodologia do Kc dual, com valores de Kcb (Kc basal da cultura) iguais $0,15,1,0$ e 0,7 para a abóbora, nas fases inicial, intermediária e final, respectivamente. Para efeito do cálculo dos Kc's médios, o ciclo da cultura foi dividido em quatro fases fenológicas: fase I: do transplantio aos 25 dias após a germinação (DAG) (25 dias); fase II: dos 25 aos 40 DAG (15 dias); fase IIII: dos 40 aos 60 DAG (20 dias) e fase IV: dos 60 aos 76 DAG (16 dias).

Durante o ciclo da cultura foram realizadas quatro coletas de plantas, aos 18, 28, 42 e 56 DAG; ao final do ciclo, as plantas foram coletadas e se determinaram a massa seca da parte vegetativa (caule + folha), frutos e da parte aérea (caule + folha + frutos), cujos resultados são expressos em $\mathrm{kg} \mathrm{ha}^{-1}$. O material vegetal coletado foi secado em estufa de circulação forçada de ar, a $65^{\circ} \mathrm{C}$, até peso constante sendo, em seguida, triturado em moinho tipo Willey (peneira de $2 \mathrm{~mm}$ ) e acondicionado em recipientes fechados para, posteriormente, serem analisados quimicamente.

Para determinação dos teores de nutrientes $(\mathrm{P}, \mathrm{K}, \mathrm{Ca}$ e $\mathrm{Mg}$ ) das frações parte vegetativa (caule + folha) e frutos das plantas, amostras de 0,4 $\mathrm{g}$ foram digeridas com ácido sulfúrico (EMBRAPA, 1997) e utilizadas para posterior determinação dos teores de $\mathrm{Ca}$ e Mg por absorção atômica; $\mathrm{P}$ por colorimetria, utilizando-se o método do complexo fosfo-molíbdico em meio redutor e K por fotometria de emissão de chama (EMBRAPA, 1997). O teor de nitrogênio foi determinado em parte do digerido com ácido sulfúrico, pelo método Kjeldahl (EMBRAPA, 1997). Com base nos resultados obtidos determinaram-se o acúmulo dos nutrientes nas plantas, a exportação de nutrientes com base no acúmulo de nutrientes e a massa seca dos frutos.

Para avaliar os efeitos da salinidade na nutrição da abóbora adotou-se o tempo de coleta como segundo fator, em esquema de parcela sub-dividida. Os resultados obtidos foram submetidos às análises de variância e de regressão e, de acordo com o nível de significância; no teste F, para os níveis de salinidade e doses de fósforo, procedeu-se à análise de regressão polinomial, utilizando-se o nível de 0,01 ou 0,05 de probabilidade, apresentados os modelos polinomiais de melhor ajuste.

\section{RESULTADOS E DISCUSS ÃO}

\section{Teores de macronutrientes no tecido vegetal}

Houve interação significativa entre os fatores salinidade da água de irrigação e épocas de avaliação para os teores de potássio (KPV) e cálcio (CaPV), a nível de significância de 5\% de probabilidade, enquanto para os teores de nitrogênio (NPV), fósforo (PPV) e magnésio (MgPV), não houve interação significativa $(p>0,05)$. Avaliando-se o efeito de cada fator isoladamente, constatou-se efeito significativo da salinidade sobre KPV, a nível de significância de $1 \%$ de probabilidade, não afetando significativamente os demais nutrientes.

As equações de regressão, relacionando-se o teor de nutrientes ao longo do ciclo da cultura, são mostradas na Tabela 2, sendo apresentada equação média para os casos em que não houve interação significativa.

Tabela 2. Equações de regressão relacionando-se os teores de nitrogênio, fósforo, potássio, cál cio e magnésio no tecido vegetal da abobora ao longo do ciclo da cultura irrigada com água de diferentes níveis de salinidade

\begin{tabular}{|c|c|c|}
\hline Nutrientes & Equações de regressão & \\
\hline Nitrogênio & $N($ Médio $)=-0,403^{* *} x+52,93$ & $R^{2}=0,99$ \\
\hline Fósforo & $\begin{array}{l}P\left(S_{1}\right)=-0,0076^{* *} x^{2}+0,56 * * x-4,10 \\
P\left(S_{2}\right)=-0,0038^{* *} x^{2}+0,25^{* *} x+0,55 \\
P\left(S_{3}\right)=-0,0061^{* *} x^{2}+0,42^{* * x} x-1,62 \\
P\left(S_{4}\right)=-0,0051^{* *} x^{2}+0,34^{* *} x-0,93 \\
P\left(S_{5}\right)=-0,0036^{* *} x^{2}+0,24 * * x+0,45\end{array}$ & $\begin{array}{l}\mathrm{R}^{2}=0,98 \\
\mathrm{R}^{2}=0,89 \\
\mathrm{R}^{2}=0,99 \\
\mathrm{R}^{2}=0,86 \\
\mathrm{R}^{2}=0,94\end{array}$ \\
\hline Potássio & $K($ M édio $)=-0,021 * x^{2}+1,35 * x+18,93$ & $R^{2}=0,99$ \\
\hline Cálcio & Ca (Médio) $=0,53^{* *} x-4,98$ & $R^{2}=0,96$ \\
\hline Magnésio & $\begin{array}{l}\operatorname{Mg}\left(S_{1}\right)=-0,0027^{* *} x^{2}+0,20 * * x+2,29 \\
M g\left(S_{2}\right)=-0,0026^{* *} x^{2}+0,21^{* *} x+2,24 \\
M g\left(S_{3}\right)=-0,0041 * * x^{2}+0,30 * * x+1,30 \\
M g\left(S_{4}\right)=-0,0043^{* *} x^{2}+0,32 * * x+1,18 \\
M g\left(S_{5}\right)=N S\end{array}$ & $\begin{array}{l}R^{2}=0,53 \\
R^{2}=0,51 \\
R^{2}=0,99 \\
R^{2}=0,99\end{array}$ \\
\hline
\end{tabular}

O teor de nitrogênio no tecido vegetal da abóbora diminuiu linearmente durante o ciclo da cultura, notando-se redução em cerca de $0,40 \mathrm{~g} \mathrm{~kg}^{-1}$ de $\mathrm{N}$ para cada dia de desenvolvimento. $\mathrm{O}$ maior teor de $\mathrm{N}$ foi obtido na primeira época de avaliação (18 DAG) com 45, $0 \mathrm{~g} \mathrm{~kg}^{-1}$, e o menor valor, aos $56 \mathrm{DAG}$, com $29,6 \mathrm{~g} \mathrm{~kg}^{-1}$, observando-se uma redução de $34,2 \%$ (Figura 1A). 
A.
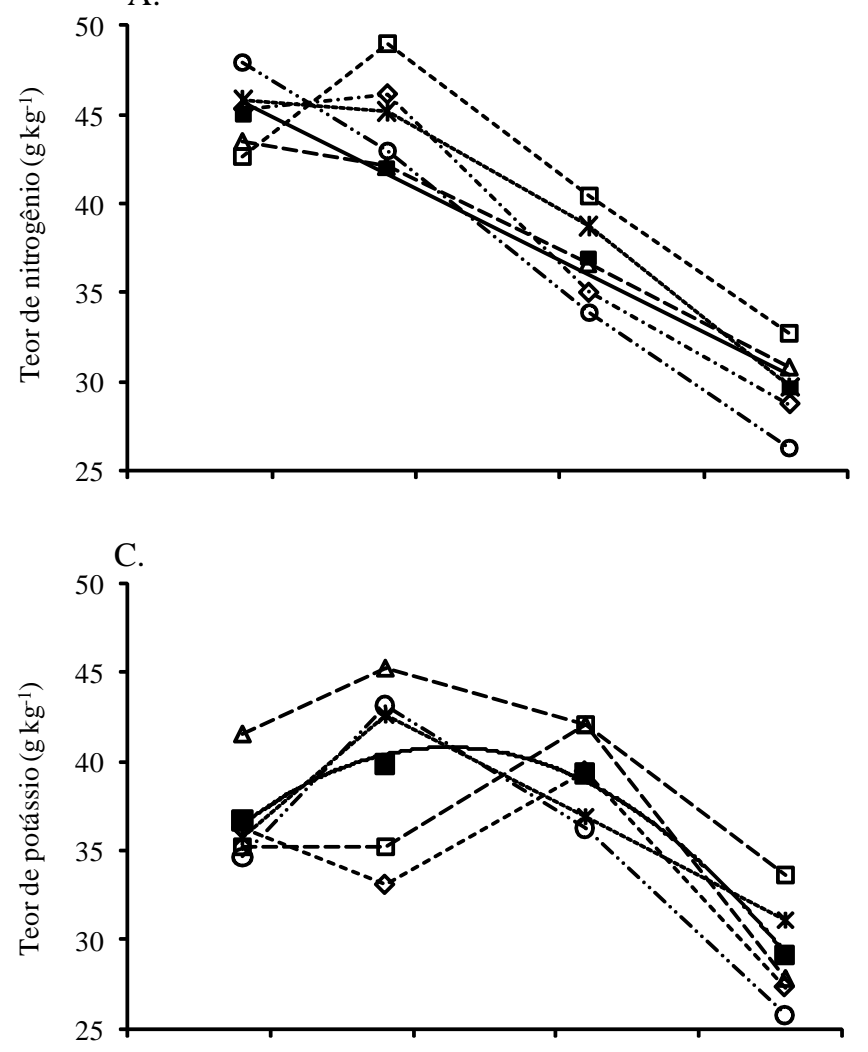

E.

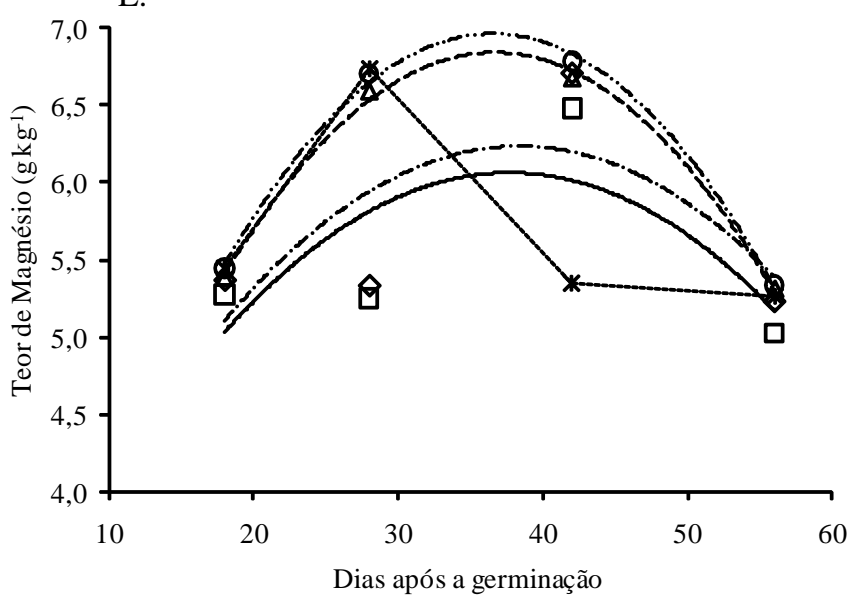

B.

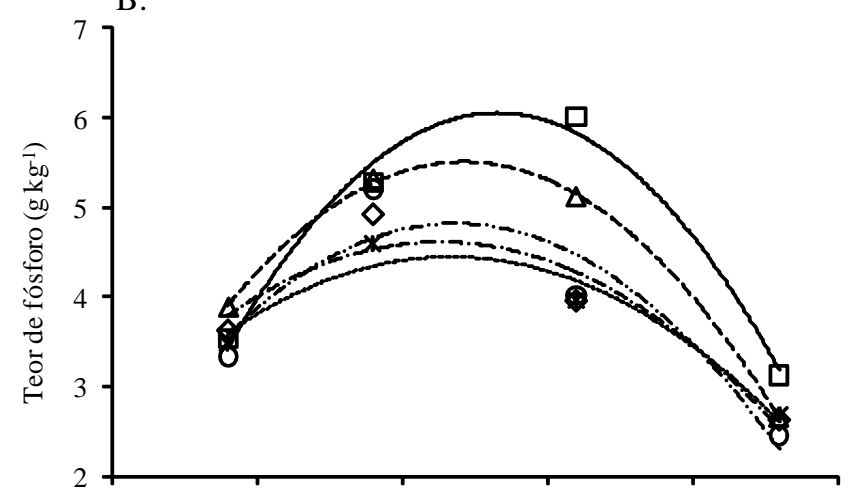

D.

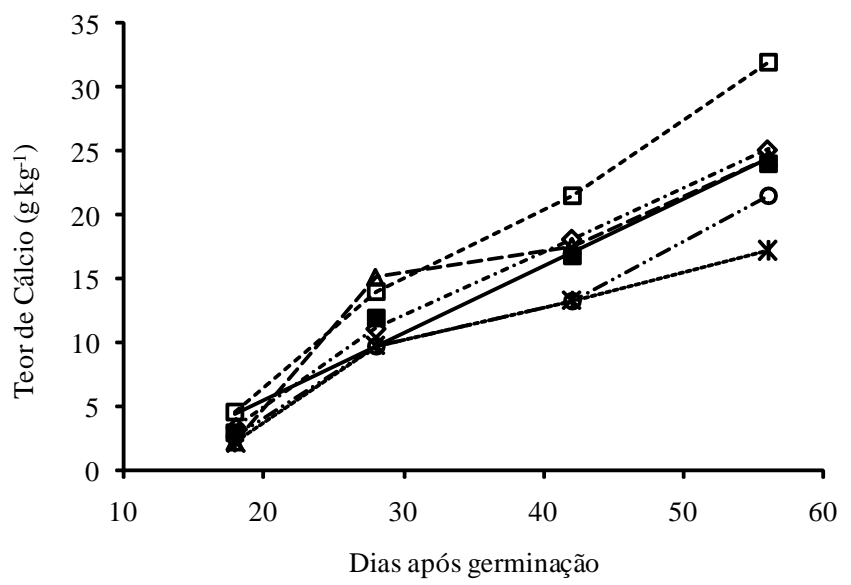

Figura 1. Teores de nitrogênio $(A)$, fósforo $(B)$, potássio $(C)$, cálcio $(D)$ e magnésio $(E)$ no tecido vegetal, ao longo do ciclo da abóbora irrigada com águas de diferentes níveis de salinidade

A redução na concentração de $\mathrm{N}$ no tecido foliar pode estar relacionada ao efeito diluição, em virtude do maior acúmulo de massa seca nas folhas, no final do ciclo da cultura. Resultados semelhantes foram observados para diferentes culturas de interesse comercial. Maia et al. (2005), também verificaram que o teor de $\mathrm{N}$ na matéria seca das folhas de melão diminuiu linearmente com a idade da planta e que não houve efeito da salinidade sobre a concentração de N. Os teores de $\mathrm{N}$ no tecido foliar obtidos neste trabalho, para todos os tratamentos, indicam que as plantas se apresentaram satisfatoriamente nutridas, de acordo com a literatura especializada. Jones Júnior et al. (1991), admitem como suficientes para a mesma espécie os teores de 40 a $60 \mathrm{~g} \mathrm{~kg}^{-1}$ na massa seca do limbo foliar.

Ao se avaliar o teor foliar de P durante o ciclo da cultura, verificou-se que o modelo quadrático foi o de melhor ajuste, para todos os níveis salinos estudados $(\mathrm{p}<0,01)$, com teor crescente de $\mathrm{P}$, até determinado nível, em resposta ao aumento de salinidade. Assim, o maior teor de P foi estimado aos 37 DAG para $\mathrm{S}_{1}, 34$ DAG para $\mathrm{S}_{2}$ e $\mathrm{S}_{3}$, e aos 33 DAG para $\mathrm{S}_{4}$ e $\mathrm{S}_{5}$, sendo obtidos teores de P equivalentes a 6,2; 3,6; 5,6; 4,7 e 4,5 $\mathrm{g} \mathrm{kg}^{-1}$, para $\mathrm{S}_{1}, \mathrm{~S}_{2}, \mathrm{~S}_{3}, \mathrm{~S}_{4}$ e $\mathrm{S}_{5}$, respectivamente. Os menores teores de $\mathrm{P}$ foram obtidos na última época de avaliação (56 DAG), com a maior redução ocorrendo nas plantas irrigadas 
com a água de salinidade $\mathrm{S}_{2}(56,7 \%)$, e a menor redução, com a $\mathrm{S}_{5}(41,6 \%)$ (Figura 1B). Trabalhos desenvolvidos por Lacerda et al. (2006) e Neves et al. (2009) demonstraram que os teores de $\mathrm{P}$ em plantas cultivadas em ambientes salinos variam durante o crescimento e o desenvolvimento da cultura.

A redução da concentração de $\mathrm{P}$ no tecido foliar se deveu, provavelmente, em razão dos efeitos de força iônica, que reduzem a atividade do fosfato na solução do solo, a elevada adsorção do fosfato e a diminuição da solubilidade desse mineral, em virtude do aumento dos níveis de $\mathrm{Na}$ e de $\mathrm{Cl}$ no solo. Silva et al. (1999) verificaram teor foliar de P de 4,6 $\mathrm{g} \mathrm{kg}^{-1}$ em abóbora híbrida (Tetsukabuto); valores esse bem próximos aos obtidos neste trabalho.

Os resultados observados no presente trabalho foram semelhantes aos obtidos por esses autores, principalmente quanto ao teor de P; no entanto, diferem em relação à época de maior concentração. Por outro lado, Jones Júnior et al. (1991) consideraram teores de $\mathrm{P}$ entre 3,0 e 5,0 $\mathrm{g} \mathrm{kg}^{-1}$ adequados para a cultura da abóbora, valores próximos aos obtidos neste trabalho.

No que diz respeito aos teores de $\mathrm{K}$ no tecido foliar da abóbora, houve um aumento inicial, atingindo o máximo teor $\left(40,6 \mathrm{~kg} \mathrm{ha}^{-1}\right)$ aos 32 dias (DAG), enquanto o menor teor estimado foi de $29,1 \mathrm{~kg} \mathrm{ha}^{-1}$, no final do período de avaliação. Comparando-se os extremos, verificou-se uma redução de $28,4 \%$, ao final do ciclo da cultura (Figura 1C). A diminuição do teor de $\mathrm{K}$ com o tempo se deveu, provavelmente, ao efeito diluição desse nutriente no tecido vegetal da planta. Este efeito é caracterizado quando a taxa de crescimento relativo de matéria seca é superior à taxa de absorção relativa do nutriente. Folegatti $\&$ Blanco (2000), relatam que o excesso de sais na solução do solo modifica as atividades metabólicas das células no processo de alongamento celular, limitando a elasticidade da parede celular, reduzindo o alongamento da célula e, como consequência, o crescimento da planta.

Quanto à concentração de Ca no tecido foliar da abóbora, ocorreu um aumento significativo nesse parâmetro em todas as épocas estudadas, com valor máximo de $24,7 \mathrm{~g} \mathrm{~kg}^{-1} \mathrm{de} \mathrm{Ca}$, observado aos 56 DAG. Este valor corresponde a um incremento de $442 \%$ em relação à primeira época de avaliação (18 DAG), na qual se observou teor de $4,6 \mathrm{~g} \mathrm{~kg}^{-1}$ no tecido foliar (Figura 1D). Esses teores estão dentro da faixa considerada suficiente para C. pepo por Jones Júnior et al. (1991), ou seja, de 12 a $25 \mathrm{~g} \mathrm{~kg}^{-1}$ de Ca na matéria seca de folhas novas completamente expandidas.

O padrão de distribuição do $\mathrm{Ca}$ em favor da parte vegetativa é, portanto, resultado do transporte exclusivo pelo xilema, sendo conduzido pela corrente transpiratória (Prado, 2008), assim, a redução na transpiração em consequencia do estresse salino pode provocar desbalanço deste nutriente nas plantas.

$\mathrm{O}$ teor de $\mathrm{Mg}$ no tecido foliar em plantas de abóbora foi afetado significativamente pela salinidade da água de irrigação. Verificou-se, também, efeito significativo para a interação entre salinidade e épocas de avaliação. Realizou-se, desta forma, o desdobramento, visando avaliar o efeito da salinidade em cada época. Equações quadráticas foram ajustadas para todos os níveis salinos e se verificou diferença quanto à época de maior concentração de Mg no tecido foliar, que ocorreu aos 37 DAG, para os níveis $\mathrm{S}_{1}, \mathrm{~S}_{2}, \mathrm{~S}_{3}$ e $\mathrm{S}_{4}$, e aos 31 DAG para o $\mathrm{S} 5$. O máximo teor de $\mathrm{Mg}$ na folha para os níveis $\mathrm{S}_{1}, \mathrm{~S}_{2}$ e $\mathrm{S}_{5}$ foi de $6,1 \mathrm{~g} \mathrm{~kg}^{-1}$; já para os níveis $\mathrm{S}_{3}$ e $\mathrm{S}_{4}$ foi de $7,0 \mathrm{~g} \mathrm{~kg}^{-1}$. Considerando-se o período de máxima concentração em cada salinidade com a primeira época de avaliação, verificou-se aumento de $17,3 \%$ para $\mathrm{S}_{1}$ e $\mathrm{S}_{2}, 21,4 \%$ para $\mathrm{S}_{3}$ e $\mathrm{S}_{4}$, e 5,2\% para $\mathrm{S}_{5}$ (Figura 1E). O magnésio, embora em menores quantidades que o cálcio, acumulou-se preferencialmente na parte aérea.

Esses resultados diferem dos obtidos por Maia et al. (2005) que, avaliando teores de nutrientes em meloeiro irrigado com água salina, verificaram redução do teor de $\mathrm{Mg}$ em resposta ao aumento da salinidade. Para todas as salinidades estudadas o teor de Mg no tecido foliar da abóbora pôde ser considerado adequado. De acordo com Jones Júnior et al. (1991), teores de $\mathrm{Mg}$ no tecido foliar são considerados adequados em valores variando de 3 a $10 \mathrm{~g} \mathrm{~kg}^{-1}$. Este crescimento no teor do $\mathrm{Mg}$ com o incremento da salinidade pode estar associado ao Mg contido na água de irrigação, haja visto que sua concentração era maior quanto maior era também a CE da água de irrigação.

Esses resultados evidenciam o efeito deletério da salinidade sobre as plantas, resultando em redução no desenvolvimento das plantas e nos teores de macronutrientes catiônicos (Garcia et al., 2007; Baghalian et al., 2008). De acordo com alguns autores, o estresse nutricional em plantas sob estresse salino pode estar associado ao acúmulo excessivo de determinados íons e à redução na aquisição de outros, em virtude das alterações na disponibilidade de nutrientes, da competição no processo de absorção e à inibição do transporte na planta (Blanco et al., 2008; Neves et al., 2009; Gurgel et al., 2010).

\section{Acúmulo e partição de macronutrientes}

A massa seca das plantas foi reduzida com o aumento da salinidade da água de irrigação, com redução total entre o maior e menor nível salino, na ordem de $37,6 \%$, sendo a massa seca dos frutos e da parte vegetativa reduzida em 41,9 e 23,3\%, respectivamente. Esses resultados demonstram que o efeito deletério da salinidade é mais evidente na translocação de fotoassimilados para os frutos, com efeito direto no acúmulo de massa da parte aérea (Tabela 3 ).

A menor produção de fotoassimilados pelas plantas cultivadas em condições salinas reflete o efeito da redução do potencial osmótico da solução do solo, inibindo a absorção de água pela planta (Figueirêdo et al., 2009) e, consequentemente, reduzindo seu crescimento. Resultados semelhantes foram obtidos por outros autores trabalhando com outra cucurbitácea, como melão (Porto Filho et al., 2006; Medeiros et al., 2007; Gurgel et al., 2010) e pepino (Medeiros et al., 2009).

De forma semelhante à massa seca, o acúmulo de macronutrientes também foi reduzido em função do aumento da salinidade da água de irrigação, comportamento que pode ser atribuído ao fato do total de nutrientes acumulado no tecido vegetal estar diretamente correlacionado com o acúmulo de massa seca. O efeito da salinidade foi maior na absorção de Ca, $\mathrm{Ne} \mathrm{K}$, com reduções de 50,5, 30,4 e 22,5\%, respectivamente, nas plantas irrigadas com água de maior salinidade, em comparação com as plantas irrigadas com água menos salina (Tabela 3). Para P e Mg, foram observadas reduções totais de 16,4 e 14,4\%. Verifica-se, ainda, que a redução na acumulação 
Tabela 3. A cúmulo ( $\left.\mathrm{kg} \mathrm{ha}^{-1}\right)$ e partição (\%) de matéria seca e de macronutrientes pela abóbora irrigada com água de diferentes níveis de salinidade, em valores absolutos relativos dentro da planta

\begin{tabular}{|c|c|c|c|c|c|c|}
\hline & \multirow{2}{*}{ Matéria seca } & \multicolumn{5}{|c|}{ Nutriente } \\
\hline & & N & $\mathbf{P}$ & K & $\mathrm{Ca}$ & $\mathrm{Mg}$ \\
\hline \multicolumn{7}{|c|}{ Salinidade da água $=0,66 \mathrm{dS} \mathrm{m}^{-1}$} \\
\hline MSPV & 1070,3 & 29,2 & 3,4 & 38,0 & 38,4 & 5,1 \\
\hline MSF & 3516,8 & 43,5 & 12,5 & 88,8 & 3,7 & 4,6 \\
\hline MSPA & 4587,1 & 72,7 & $\begin{array}{r}15,9 \\
(\%)\end{array}$ & 126,8 & 42,0 & 9,7 \\
\hline MSPV & 23,3 & 40,1 & 21,6 & 30,0 & 91,3 & 52,7 \\
\hline MSF & 76,7 & 59,9 & 78,4 & 70,0 & 8,7 & 47,3 \\
\hline MSPA & 100,0 & 100,0 & 100,0 & 100,0 & 100,0 & 100,0 \\
\hline \multicolumn{7}{|c|}{ 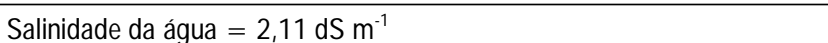 } \\
\hline MSPV & 902,5 & 23,4 & 2,5 & 29,4 & 28,6 & 4,7 \\
\hline MSF & 2609,0 & 48,2 & 13,8 & 99,0 & 4,2 & 5,6 \\
\hline MSPA & 3511,5 & 71,6 & $\begin{array}{r}16,4 \\
(\%)\end{array}$ & 128,3 & 32,9 & 10,3 \\
\hline MSPV & 25,7 & 32,6 & 15,5 & 22,9 & 87,1 & 45,9 \\
\hline MSF & 74,3 & 67,4 & 84,5 & 77,1 & 12,9 & 54,1 \\
\hline MSPA & 100,0 & 100,0 & 100,0 & 100,0 & 100,0 & 100,0 \\
\hline \multicolumn{7}{|c|}{ Salinidade da água $=3,29 \mathrm{dS} \mathrm{m}^{-1}$} \\
\hline MSPV & 789,3 & 21,1 & 2,1 & 27,3 & 28,7 & 4,1 \\
\hline MSF & 2159,7 & 46,7 & 13,9 & 94,5 & 4,5 & 5,2 \\
\hline MSPA & 2949,0 & 67,7 & $\begin{array}{r}16,0 \\
(\%)\end{array}$ & 121,8 & 33,2 & 9,3 \\
\hline MSPV & 26,8 & 31,1 & 13,2 & 22,4 & 86,4 & 44,1 \\
\hline MSF & 73,2 & 68,9 & 86,8 & 77,6 & 13,6 & 55,9 \\
\hline MSPA & 100,0 & 100,0 & 100,0 & 100,0 & 100,0 & 100,0 \\
\hline \multicolumn{7}{|c|}{ Salinidade da água $=4,11 \mathrm{dS} \mathrm{m}^{-1}$} \\
\hline MSPV & 793,3 & 18,2 & 2,2 & 25,4 & 24,3 & 4,4 \\
\hline MSF & 1767,6 & 34,1 & 9,7 & 69,6 & 3,0 & 4,3 \\
\hline MSPA & 2560,8 & 52,4 & $\begin{array}{r}11,8 \\
(\%)\end{array}$ & 95,0 & 27,2 & 8,6 \\
\hline MSPV & 31,0 & 34,8 & 18,4 & 26,8 & 89,2 & 50,6 \\
\hline MSF & 69,0 & 65,2 & 81,6 & 73,2 & 10,8 & 49,4 \\
\hline MSPA & 100,0 & 100,0 & 100,0 & 100,0 & 100,0 & 100,0 \\
\hline \multicolumn{7}{|c|}{ Salinidade da água $=4,38 \mathrm{dS} \mathrm{m}^{-1}$} \\
\hline MSPV & 821,3 & 20,6 & 2,3 & 29,0 & 18,7 & 4,4 \\
\hline MSF & 2042,3 & 30,0 & 11,1 & 69,3 & 2,1 & 3,9 \\
\hline MSPA & 2863,6 & 50,6 & $\begin{array}{r}13,3 \\
(\%)\end{array}$ & 98,3 & 20,8 & 8,3 \\
\hline MSPV & 28,7 & 40,7 & 17,1 & 29,5 & 89,9 & 53,4 \\
\hline MSF & 71,3 & 59,3 & 82,9 & 70,5 & 10,1 & 46,6 \\
\hline MSPA & 100,0 & 100,0 & 100,0 & 100,0 & 100,0 & 100,0 \\
\hline
\end{tabular}

Redução no acúmulo de massa seca e de macronutrientes na maior salinidade (\%) $\begin{array}{lllllll}\text { MSPV } & 23,3 & 29,5 & 32,4 & 23,7 & 51,3 & 13,7\end{array}$

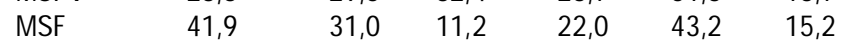

$\begin{array}{lllllll}\text { MSPA } & 37,6 & 30,4 & 16,4 & 22,5 & 50,5 & 14,4\end{array}$

MSPV - Massa seca da parte vegetativa; MSF - Massa seca dos frutos; MSPA - Massa seca da parte aérea

desses nutrientes foi semelhante nos tecidos da parte vegetativa e dos frutos, para $\mathrm{N}, \mathrm{K}$ e $\mathrm{Mg}$, com variações de menos de $2 \%$, enquanto para $\mathrm{P} \mathrm{e} \mathrm{Ca} \mathrm{foram} \mathrm{observadas} \mathrm{variações}$ na ordem de 21,2 e $8,1 \%$, respectivamente, com maiores reduções na parte vegetativa.

Os nutrientes mais absorvidos pela cultura da abóbora foram potássio, nitrogênio e cálcio, com acúmulo total de $128,3,48,2$ e $42,0 \mathrm{~kg} \mathrm{ha}^{-1}$, respectivamente, enquanto os menores valores foram constatados para magnésio $(13,9 \mathrm{~kg}$ $\left.\mathrm{ha}^{-1}\right)$ e fósforo $\left(10,3 \mathrm{~kg} \mathrm{ha}^{-1}\right)$. Trabalhando com este mesmo material genético, Medeiros (2006) também observou que o potássio e o nitrogênio foram os macronutrientes mais absorvidos pela abóbora.

Avaliando-se a partição dos nutrientes entre a parte vegetativa e os frutos, constatou-se que $\mathrm{N}, \mathrm{P}$ e $\mathrm{K}$ foram os nutrientes mais exportados para os frutos, com 64,1, 82,2 e $73,7 \%$, respectivamente, enquanto na parte vegetativa foram encontrados apenas 35,9,17,2 e $26,3 \%$, respectivamente. Verificou-se que somente $11,2 \%$ do Ca absorvido pela abóbora foram exportados para os frutos, enquanto a parte vegetativa concentrou $88,8 \%$ do total de $\mathrm{Ca}$ acumulado pela cultura. A cultura da abóbora não apresentou dreno preferencial para o magnésio, mas se observaram 50,7\% do total acumulado nos frutos e $49,3 \%$, na parte vegetativa (Tabela 3 ).

Os resultados obtidos neste trabalho são semelhantes aos encontrados por Medeiros (2006), que também constatou que os frutos concentraram a maior parte do $\mathrm{N}, \mathrm{P}$ e K absorvidos pela cultura da abóbora, com 75,6, 66,3 e 71,4\%, respectivamente, observando-se, ainda, que o Ca foi mais presente na parte vegetativa $(70,0 \%)$ e que o $\mathrm{Mg}$ não apresentou diferença considerável entre parte vegetativa e fruto, com 59,0 e 41,0\%, respectivamente. Trabalhando com a cultura da melancia, Grangeiro \& Cecílio Filho (2005), verificaram que os frutos participaram com $77 \%$ do N, $82 \%$ do P, $76 \%$ do K, $17 \%$ do Ca e $41 \%$ do $\mathrm{Mg}$.

A maior participação de Ca na parte vegetativa se deve às suas características na planta pois, após a absorção, ele é transportado até o xilema e, de forma passiva, para a parte aérea das plantas, por meio exclusivamente da corrente transpiratória (Prado, 2008). Ressalta-se, ainda, que a translocação do Ca na planta ocorre junto com a água, sendo afetada pela taxa de transpiração. Desta forma, órgãos que apresentam menor taxa de transpiração, como folhas novas e frutos, recebem menores quantidades de $\mathrm{Ca}$.

\section{ConClusões}

1. Os maiores teores de fósforo, potássio e magnésio no tecido vegetal da abóbora, foram obtidos na fase intermediária do ciclo da cultura.

2. Os teores de nitrogênio diminuíram enquanto os teores de cálcio aumentaram, ao longo do ciclo da cultura.

3. A massa seca e o acúmulo de macronutrientes na cultura da abóbora foram reduzidos em função do aumento da salinidade da água de irrigação, proporcionando diminuição para a água mais salina $\left(\mathrm{CE}=4,38 \mathrm{dS} \mathrm{m}^{-1}\right)$ em comparação com a menos salina $\left(\mathrm{CE}=0,66 \mathrm{dS} \mathrm{m}^{-1}\right)$ de 37,6\%, 50,5, 30,4, 22,5, 16,4 e 14,4\%, para massa seca, Ca, N, K, P e Mg, respectivamente.

4. A absorção de nutrientes pela cultura da abóbora ocorreu na seguinte ordem: $\mathrm{K}>\mathrm{N}>\mathrm{Ca}>\mathrm{P}>\mathrm{Mg}$, obtendo-se o total de $126,5,72,7,42,0,15,5$ e $9,7 \mathrm{~kg} \mathrm{ha}^{-1}$, sendo exportados para os frutos cerca de $64,1,82,8,73,7,11,2$ e $50,7 \%$, respectivamente.

\section{Agradecimentos}

Os autores agradecem ao $\mathrm{CNPq}$, pelo apoio financeiro necessário ao desenvolvimento dos trabalhos, através do Edital Universal 02/2006 (Processo 476688/2006-0) e Edital PQ 2007 (Processo 304868/2007-8) 


\section{LITERATURA CITADA}

Allen, R. G.; Pereira, L. S.; Raes, D.; Smith, M. Crop evapotranspiration: Guidelines for computing crop water requirements. Rome: FAO, 1998, 297p. FAO. Irrigation and Drainage Paper, 56.

Baghalian, K.; Haghiry, A.; Naghavi, M. R.; Mohammadi, A. Effect of saline irrigation water on agronomical and phytochemical characters of chamomile (Matricaria recutita L.). Scientia Horticulturae, v.116, p.437-441, 2008.

Blanco, F. F.; Folegatti, M. V.; Henriques Neto, D. Doses de N e K no tomateiro sob estresse salino: I. Concentração de nutrientes no solo e na planta. Revista Brasileira de Engenharia Agrícola e Ambiental, v.12, p.26-33, 2008.

Cardona, A.; Carrillo-Rivera, J. J.; Huizar-Alvarez, R.; GranielCastro, E. Salinization in coastal aquifers of arid zones: An example from Santo Domingo, Baja California Sur, Mexico. Environmental Geology, v.45, p.350-366, 2004.

Carmo Filho, F.; Oliveira, O. F. Mossoró: Um município do semiárido: caracterização climática e aspecto florístico. Mossoró: ESAM, 1989. 62p. Coleção Mossoroense, 672, série B.

EMBRAPA - Empresa Brasileira de Pesquisa Agropecuária. Sistema brasileiro de classificação de solos. Brasília: EMBRAPA, 1999. 412p.

EMBRAPA - Empresa Brasileira de Pesquisa Agropecuária Centro Nacional de Pesquisa de Solos. Manual de métodos de análise de solos. 2.ed. Rio de Janeiro: Embrapa CNPS, 1997. 212p.

Figueirêdo, V. B.; Medeiros, J. F. de; Zocoler, J. L.; Espínola Sobrinho, J. Evapotranspiração da cultura da melancia irrigada com água de diferentes salinidades. Engenharia Agrícola, v.29, p.231-240, 2009.

Folegatti, M. V.; Blanco, F. F. Desenvolvimento vegetativo do pepino enxertado irrigado com água salina. Scientia Agricola, v.57, p.451-457, 2000.

Freire, A. L. O.; Rodrigues, T. J. D. A salinidade do solo e seus reflexos no crescimento, nodulação e teores de N, K E Na em leucena (Leucaena leucocephala (Lam.) de Vit.). Revista Engenharia Ambiental: Pesquisa e Tecnologia, v.6, p.163$173,2009$.

Garcia, G. O.; Ferreira, P. A.; Miranda, G. V.; Neves, J. C. L.; Moraes, W. B.; Santos, D. B. Teores foliares dos macronutrientes catiônicos e suas relações com sódio em plantas de milho sob estresse salino. Idesia, v.25, p.93-106, 2007.

Grangeiro, L. C.; Cecílio Filho, A. B. Acúmulo e exportação de Macronutrientes em melancia sem sementes. Horticultura Brasileira, v.23, p.763-767, 2005.

Grattan, S. R.; Grieve, C. M. Salinity-mineral nutrient relations in horticultural crops. Scientia Horticulturae, v.78, p.127$157,1999$.

Gurgel, M. T.; Uyeda, C. A.; Gheyi, H. R.; Oliveira, F. H. T.; Fernandes, P. D.; Silva, F. V. Crescimento de meloeiro sob estresse salino e doses de potássio. Revista Brasileira de Engenharia Agrícola e Ambiental, v.14, p.3-10, 2010.
Jones Júnior, J. B.; Wolf, B.; Mills, H. A. Plant analysis handbook: a practical sampling, preparation, analysis and interpretation guide. Athens: Micro- Macro, 1991. 213p.

Lacerda, C. F. de.; Morais, M. M. M.; Prisco, J. T.; Gomes Filho, E.; Bezerra, M. A. Interação entre salinidade e fósforo em plantas de sorgo forrageiro. Revista Ciência Agronômica, v.37, p.258-263, 2006.

Maia, C. E.; Morais, E. R. C.; Porto Filho, F. Q.; Gheyi, R. H.; Medeiros, J. F. de. Teores foliares de nutrientes em meloeiro irrigado com águas de diferentes salinidades. Revista Brasileira de Engenharia Agrícola e Ambiental, v.9, p.292295, 2005.

Medeiros, J. F. de; Silva, M. C. C.; Sarmento, D. H. A.; Barros, A. D. Crescimento do meloeiro cultivado sob diferentes níveis de salinidade, com e sem cobertura do solo. Revista Brasileira de Engenharia Agrícola e Ambiental, v.11, p.248-255, 2007.

Medeiros, M. A. Acúmulo e exportação de nutrientes em abóbora butternut. Mossoró: UFERSA, 2006. 23p. Monografia

Medeiros, P. R. F.; Duarte, S. N.; Dias, C. T. S. Tolerância da cultura do pepino a salinidade em ambiente protegido. Revista Brasileira de Engenharia Agrícola e Ambiental, v.13, p.406-410, 2009.

Neves, A. L. R.; Lacerda, C. F. de; Guimarães, F. V. A.; Gomes Filho, E.; Feitosa, D. R. C. Trocas gasosas e teores de minerais no feijão-de-corda irrigado com água salina em diferentes estádios. Revista Brasileira de Engenharia Agrícola e Ambiental, v.13, p.873-881, 2009.

Porto Filho, F. Q.; Medeiros, J. F. de; Gheyi, H. R.; Matos, J. de A.; Souza, E. R.; Sousa Neto, E. R. Crescimento do meloeiro irrigado com águas de diferentes salinidades. Horticultura Brasileira, v.24, p.334-341, 2006.

Prado, R. M. Nutrição de plantas. São Paulo: UNESP, 2008. $407 \mathrm{p}$.

Silva, J. V.; Lacerda, C. F.; Azevedo Neto, A. D. de; Costa, P. H. A.; Prisco, J. T.; Enéas Filho, J.; Gomes Filho, E. Crescimento e osmoregulação em dois genótipos de sorgo forrageiro submetidos ao estresse salino. Revista Ciência Agronômica, v.33, p.125-131, 2003.

Silva, M. O.; Freire, M. B. G. S.; Mendes, A. M. S.; Freire, F. J.; Sousa, C. E. S.; Góes, G. B. Crescimento de meloeiro e acúmulo de nutrientes na planta sob irrigação com águas salinas. Revista Brasileira de Engenharia Agrícola e Ambiental, v.12, p.593-605, 2008.

Silva, N. F.; Fontes, P. C.; Ferreira, F. A.; Cardoso, A. A. Adubação mineral e orgânica da abóbora híbrida II. Estado nutricional e produção. Pesquisa Agropecuária Tropical, v.29, p.19-28, 1999.

SIN - Rede Brasileira de Centros Internacionais de Negócios. Exportações do RN 2005. http://www.fiern.org.br/negócios/ Exportação\%20DO\%20RN\%202005.polf. 05 Mar 2006.

Tester, M.; Davenport, R. $\mathrm{Na}^{+}$tolerance and $\mathrm{Na}^{+}$transport in higher plants. Annals of Botany, v.91, p.503-527, 2003.

van Genuchten, M. Th. A closed-form equation for predicting the hydraulic conductivity of unsaturated soils. Soil Science Society of America Journal, v.44, p.892-898, 1980. 